Nutritional problems of the Third World

Development, Reform, and Malnutrition in Chile. By P. Hakim and G. Solimano. Pp. 91. (MIT Press: Cambridge, Massachusetts, and London, 1978.) $\$ 10$; £7.

THERE is a real need for examples of national programmes that actually work within the economic restraints of developing countries. Development should benefit people, and the best measure of an improved quality of life is the elimination of malnutrition, which results pimarily from poverty and ignorance. It is not enough to increase food production when people cannot buy it, nor to raise incomes when people do not know what to buy. The Chilean example has much to commend it, as an attempt was made to reduce malnutrition at a time of social change. The Allende régime lasted three short years, but during this period it attempted fundamental changes in economic policy by bringing large sections of industry under state ownership and extending land reform. A general redistribution of income was achieved, unemployment was reduced, and the social services were made more available to the low income groups. Food consumption increased by about $10 \%$, although largely as a result of food imports, and the distribution of free milk by the Government was trebled. In other words all the elements for the successful improvement of nutritional status appeared to be present. The question is, did it happen?

The authors of this book are frankly pessimistic, although a proper evaluation was not carried out. The free milk scheme, the major topic of their book, provided distribution from schools and clinics which were not available to all the population thereby giving preference to the richer urban community: the milk reached only $70 \%$ of the eligible beneficiaries. Although it was provided to the most vulnerable age groups, it was often shared within the family and occasionally sold. Nevertheless, 40,000 tonnes of dried milk was distributed annually. A careful analysis of Chile's nutritional problems reveals, however, that they are due to a low consumption of food rather than a lack of particular nutrients and the emphasis on protein should be challenged.

It is self-evident that the primary need of starving children is food. In retrospect, the authors recognise the lack of scientific rationale for the milk programme and admit that the present oppressive government, which is now distributing 25,000 tonnes but with added fat, might be better advised. The promotion of protein-rich foods derives from old-fashioned nutritonal ideas which were outmoded at the time of Allende, and that of free milk from socio-political targets which were unrealistic for the economy. All of this is examined in detail in the book.

It could be argued that the period was too short to expect any change in nutritional status, but this is not so. The growth rate of deprived children shows a marked improvement when they are well fed: a nutritional programme in Korea has led over seven years to a national increase of $3 \mathrm{~cm}$ in average height and $1 \mathrm{~kg}$ in average weight of children. Also, in Ethiopia an applied nutritional programme halved the infant mortality rate in three years. Simple statistics of this kind are essential for evaluation-relatively easy to obtain, but not apparently available from Chile over the relevant period. Such data may not be as easy to interpret as the results of laboratory experiments where everything is controlled, but it is more satisfying to try to explain successes than failures.

The authors are well aware of the economic, educational and medical

\section{Chemical and enzymic catalysis}

Transition States of Biochemical Processes, Edited by R. D. Gandour and R. L. Schowen. Pp.616. (Plenum: New York and London, 1978.)

THE theory of absolute reaction rates, commonly known as transition state theory has been perhaps the most influential principle in the development of our knowledge of reaction mechanisms in solution. This book consists of a series of chapters written by 21 authors on the theories and methods used to investigate chemical and enzymic catalysis.

The book is written in four parts. In part $I$ the assumptions in transition state theory are examined and its application to chemical kinetics and mechanisms discussed. When enzymecatalysed reactions are considered, the fundamentalist view is adopted, namely that catalysis originates from stabilisation of the transition state through binding to the catalyst.

In part II, which is the longest section of the volume, the main techniques used to investigate transition state structure and properties are introduced. Rightly this section is dominated by the application of isotope effects. Primary, secondary and solvent isotope effects of hydrogen are dis- factors influencing nutritional status and suggest that all were improving during Allende's time but the reader, may not be entirely convinced. In particular, although they distinguish between preventative and curative medicine, they do not stress the difference between the strictly medical and public health engineering, for example, water and sanitation. The latter is probably more effective than vaccination programmes albeit much more expensive. Similarly the educational programmes were largely through the mass media and possibly did not reach or convince the most socially deprived. Finally, action to redistribute wealth which satisfied the intellectuals, may not have been as effective as claimed. But certainly the position has deteriorated since 1973 and the brave efforts of Allende reported here are worthy of this objective documentation.

The book will interest those concerned with recent Chilean history, but will be most valuable to those grappling with nutritional problems of the Third World.

D. S. Miller

D. S. Miller is a Research Fellow in the Department of Nutrition at Queen Elizabeth College, University of London, UK.

cussed as well as the heavy-atom isotope effects on carbon, nitrogen, oxygen and chlorine. The first chapter of this section, however, introduces the quantum mechanical procedures which have been used to investigate enzymic transition states and reaction pathways. The last two chapters review the application of magnetic resonance techniques to investigate enzyme-ligand complexes and the mapping of reaction pathways from X-ray crytallographic data.

In part III, well studied reactions are discussed which are biochemically important. These include acyl, methyl, and phosphoryl transfer, acetal hydrolysis, decarboxylations and relevant models of enzymic reactions. In the final part, the use of inhibitors as tools to elucidate the sources of enzymic catalysis are discussed and the application of transition state information to the design of potent drugs is described.

Thus the book ranges over all the major disciplines which have contributed to the investigation of chemical and enzymic mechanisms. The editors have selected an excellent array of authors and have welded their contributions together into a text which will be of value to a wide range of chemists and biochemists.

\section{G. Lowe}

G. Lowe is Lecturer in Organic Chemistry at the University of Oxford, UK. 